\title{
43. VELOCITY AND DENSITY OF CARBONATE-RICH SEDIMENTS FROM NORTHEASTERN AUSTRALIAN MARGIN: INTEGRATION OF CORE AND LOG DATA ${ }^{1}$
}

\author{
Richard D. Jarrard, ${ }^{2,3}$ Peter D. Jackson, ${ }^{4}$ Michael Kasschau, ${ }^{5}$ and John W. Ladd ${ }^{2}$
}

\begin{abstract}
During Ocean Drilling Program (ODP) Leg 133, shipboard scientists obtained a remarkable quantity of both core and log measurements of the physical properties of carbonate-rich sediments. This suite of measurements provides a unique opportunity to evaluate the robustness of each measurement technique to variations in lithification, porosity, core disturbance (for core measurements), and hole conditions (for log measurements). Detailed quality-control, which often resulted in the deletion of erroneous data, was essential for the reliable integration of these core and log data.

In common with several previous studies, our comparison between core and in-situ velocity and density data identified pervasive patterns of bias to the core measurements, caused by removal from in-situ conditions. Velocity is particularly sensitive to this change, because the frame modulus of unlithified sediments is decreased dramatically by even slight core expansion or disturbance. The much larger number of sites considered in this study allows us to distinguish between site-specific and regional patterns of differences between core and log data. Such a comparison suggests that we still cannot reliably predict the effects of core expansion, either for ODP cores or for ODP measurements of core physical properties. In general, Leg 133 index measurements of core density are approximately in agreement with log densities, but GRAPE measurements of core density may be lower or higher than log densities.

This study has successfully integrated core and in-situ physical property measurements and developed merged velocity logs for 12 sites and merged density logs for nine sites. Each merged log extends from the seafloor to within a few meters of the bottom of the hole.
\end{abstract}

\section{INTRODUCTION}

During Ocean Drilling Program legs, shipboard scientists routinely obtain in situ records of downhole variations of velocity and density through openhole logging, but such logs are only available below the base of pipe at $\sim 70$ to 100 meters below seafloor (mbsf). In contrast, measurements of physical properties of core can be best in about the top 50 to $200 \mathrm{mbsf}$, where the advanced piston corer (APC) yields superior recovery and much less core disturbance than deeper cores obtained with the extended core barrel (XCB) or rotary core barrel (RCB). Data from downhole logs and core physical-property measurements thus are often complementary in depth coverage: each provides reliable data for a depth interval that the other technique has either not sampled, undersampled, or perhaps sampled under conditions that are less than optimum for application of that measurement technique. Further, a zone of depth overlap often exists at $\sim 70$ to $200 \mathrm{mbsf}$, where both laboratory and $\log$ measurements are plentiful and potentially reliable. This overlap zone permits comparison and evaluation of the different techniques, often with development of empirical corrections for the effect on physical properties of removal of core from in-situ to laboratory conditions.

In this chapter, we seek to capitalize on the different strengths of core and downhole log data, to achieve a comparison, reconciliation, and merging of core and log data for the carbonate-rich sediments drilled during Leg 133. During Leg 133, a remarkable quantity of both velocity and density data was collected. In addition to the routine measurements of velocity and density on a record quantity of recovered core, 12 sites have downhole velocity logs and 9 sites have density logs. By examining this large number of sites, we hope to

\footnotetext{
'McKenzie, J. A., Davies, P.J., Palmer-Julson, A., et al., 1993. Proc. ODP, Sci. Results, 133: College Station. TX (Ocean Drilling Program).

${ }^{2}$ Lamont-Doherty Geological Observatory of Columbia University, Palisades, NY 10964, U.S.A.

${ }^{3}$ Present address: Department of Geology and Geophysics, University of Utah, Salt Lake City, UT 84112, U.S.A.

${ }^{4}$ British Geological Survey, Keyworth, Nottingham NG12 5GG, U.K

${ }^{5}$ Department of Physics, Columbia University, New York, NY 10027, U.S.A.
}

distinguish between site-specific and regional patterns of data accuracy, quality-control problems, and geologic controls for both core and log measurements of physical properties.

Three direct measures of formation bulk density were obtained during Leg 133: density logs, index measurements of core density, and continuous measurements of core density utilizing the gamma-ray attenuation porosity evaluator (GRAPE). Two techniques of velocity measurement were used: velocity logs and Hamilton-Frame measurements of core velocity. Because velocity, density, and resistivity are all affected by porosity, resistivity logs were also used in our analyses. This study integrates these diverse data types to develop 12 merged velocity logs and 9 merged density logs, each of which extends from the seafloor to within a few meters of the bottom of the hole.

All sites drilled during Leg 133 included more than one hole. Here we combine data from different holes at the same site, usually without mentioning which hole these data come from. One site was cored at the beginning of Leg 133, then returned to for further coring near the end of the leg. By ODP convention, the two occupations are given different site numbers (Sites 811 and 825 ) because different navigation beacons were used. The two "sites," however, are as close together as adjacent holes at the same site normally are, and so we combined their data, referring to all data from this location as "Site 825." Detailed hole and site locations of all referenced data can be found in Davies, McKenzie, Palmer-Julson, et al. (1991).

Different facies of carbonate-rich sediments may differ considerably in their elastic properties. Clay-rich carbonates are much higher in porosity than are pure carbonates, because of inefficient packing of the platy clay minerals. Even a small percentage of clay minerals decreases velocity substantially (Han et al., 1986), because the clay minerals are much lower in rigidity than are pure carbonates. Reef debris may have undergone diagenesis prior to deposition, causing lower porosity and higher rigidity than are typical for pelagic carbonates. Because of these possible facies-dependent effects, our analyses often distinguish between three lithologic types: (1) "pelagic" sediments, which are almost entirely composed of pelagic carbonate; (2) "mixed" sediments, which are a mixture of pelagic carbonate and clay minerals; and (3) "reefal" carbonates, which may or may not include 
some pelagic carbonates. These categories are useful but somewhat arbitrary divisions of continua in relative proportions of pelagic carbonate, reef carbonate, and clay minerals.

\section{DENSITY LOGS}

Density logging during Leg 133 used the Schlumberger hothole lithodensity tool (HLDT), which irradiates the formation with gamma rays and measures the resulting flux at fixed distances from the radioactive source. Both source and receivers are pressed against the borehole wall by an eccentralizing arm. Density logs were obtained at Sites 812,814 through 817 , and 819 through 823 . Density logs were not run at two of the 12 logged sites, Sites 824 and 825 , because of both time constraints and the expectation that large hole size would degrade density log quality. The density logging tool was deployed at Site 822 , but its density log is not used here because, owing to poor hole conditions, the eccentralizing arm was not opened.

In general, density logs obtained during Leg 133 were comparable in quality to those obtained for other pelagic carbonate sites, but lower in quality than for noncarbonate sites. During drilling of unlithified pelagic carbonates, both fluid circulation and caving usually enlarge the hole substantially. XCB bit diameter is $30 \mathrm{~cm}$, but the final diameter of such holes commonly varies from 30 to $>60 \mathrm{~cm}$. The HLDT used for density logging during Leg 133 is a padtype tool having an eccentralizing arm capable of maintaining pad contact with the borehole wall to a maximum hole diameter of $46 \mathrm{~cm}$. In holes larger than $46 \mathrm{~cm}$, the pad obtains firm contact with the borehole wall only occasionally, when tool orientation is such that the pad is on the "downhill" side of the slightly deviated borehole.

Whenever pad contact is lost, density tools detect a combination of formation density and borehole-fluid density. To correct for this problem, the HLDT is compensated: discrepancies between short and long-spacing detectors provide an estimated correction for intervening fluid. The magnitude of compensation correction (DRHO, or $\Delta \rho$ ) furnishes a quality control estimate: when DRHO is less than \pm 0.1 $\mathrm{g} / \mathrm{cm}^{3}$, the count-rate ratio of the two detectors suggests good pad contact and reliable density logs, whereas higher values of DRHO indicate that large corrections have been applied and that the corrected density value may not be accurate.

Major loss of pad contact is evident not merely in DRHO logs. It is also obvious in the density log itself, as sudden decreases to very low density values, sometimes approaching water density. Such dropouts are frequent in the carbonate logs of Leg 133. Indeed, density dropouts were the dominant log error encountered during Leg 133 (Davies, McKenzie, Palmer-Julson, et al., 1991). Thus, log editing was required for all Leg 133 density logs. Such editing is subjective, both in identification of dropouts and in replacement of omitted data, yet differences in editing among most log analysts are minor in comparison to the differences between raw and edited logs.

In this study, we edited the density logs as follows. A plot of the density $\log$ as a function of depth was overlain with a plot of logarithm of formation factor, the ratio of formation resistivity to seawater resistivity. Formation factor was used as a standard because resistivity logs are probably the highest signal-to-noise logs obtained by ODP, and both density and the logarithm of resistivity are approximately linearly proportional to porosity. Density and formation-factor amplitudes were adjusted so that most of the two logs overlaid closely, then density dropouts were deleted. Most density dropouts were readily identifiable without the overlay, but the overlay permitted confident discrimination between high-porosity zones and density dropout zones.

When a deleted zone was only 1 to 5 points long, edited density values were provided by simple interpolation across the gap. Such an interpolation should be moderately accurate, because density is measured every $0.15 \mathrm{~m}$, but the vertical resolution of the HLDT tool is $\sim 0.3$ $\mathrm{m}$. Longer deleted zones were filled with "pseudodensity" values. In an adjacent zone, where the density was judged to be reliable, the relation of density to logarithm of formation factor was determined by linear regression. Pseudodensities then were generated by applying the regression relationship to the values of logarithm of formation factor within the zone that contained deleted density data. At the top of each density log, where the tool loses pad contact and enters pipe, unreliable density values were deleted, but no pseudodensity values were added. A few meters of resistivity log were obtained beneath the bottom of each density log, because the resistivity tool is the lowest tool on the geophysical tool string; thus, pseudodensities were added to the base of each density $\log$.

In Figure 1, overlays of the raw and edited density logs are shown from the nine sites that have useful density logs. We consider these final edited logs to be of good reliability overall. For example, the minor editing at Sites 814 and 817 , as well as the major editing at Site 815 , is relatively straightforward and likely to be accurate. We caution, however, that these densities are only approximate in the longer $(>10 \mathrm{~m})$ intervals of pseudodensities, particularly if rare lithologic changes degrade our assumption that porosity is the dominant variable that controls both density and formation factor. In particular, pseudodensities may be inaccurate by as much as $0.05 \mathrm{~g} / \mathrm{cm}^{3}$ in the lithologically controlled dropouts within the intervals $240-260 \mathrm{mbsf}$ at Site 819, 340-355 mbsf at Site 820, and 305-320 mbsf at Site 821 . At Site 823 above $\sim 48 \mathrm{mbsf}$, hole conditions were so poor and dropouts so pervasive (Fig. 1) that the density log was deleted and no pseudodensity was substituted.

\section{CORE DENSITY}

GRAPE density measurements are based on nearly the same technique as log density measurements; only the source-receiver geometry is different. Whole cores are passed between a gamma-ray source and detector; the quantity of attenuated gamma rays is proportional to the intervening mass, and the sample volume is known from the core liner size. The ODP technique is described in detail by Boyce (1976).

GRAPE density measurements are routinely performed for ODP cores obtained with the APC, but rarely for ODP cores obtained with either the XCB or RCB. This difference is because APC cores are relatively undisturbed by the coring process, but core disturbance is common in XCB and RCB cores. During Leg 133, all APC and some $\mathrm{XCB}$ cores were subjected to GRAPE measurements.

In spite of, and perhaps partially because of, the huge quantity of ODP GRAPE measurements, they are probably the least utilized measurement performed by ODP. GRAPE measurements are only occasionally displayed in Initial Reports volumes. The problem is that they are very sensitive to core disturbance: density dropouts occur at the boundaries of $1.5-\mathrm{m}$ sections and wherever disturbance has increased porosity. Disturbance-induced porosity increases occur near the tops of many APC cores, between the core and liner in most XCB and RCB cores, and in the "biscuits and gravy" recovery characteristic of many $\mathrm{XCB}$ and $\mathrm{RCB}$ cores. Consequently, utilization of GRAPE data for any site should be preceded by the deletion of hundreds of erroneous data points. Figure 2 is an example of raw GRAPE data and of the same data set after subjective deletion of density dropouts.

Edited GRAPE data can be evaluated by comparing GRAPE records from adjacent holes at the same site. Core breaks at adjacent holes are deliberately staggered; thus, any inadequacy in either data accuracy or editing will create interhole discrepancies in the character of the GRAPE records. In Figure 3, edited GRAPE records are shown from two holes at each of Sites 817 and 823, where GRAPE measurement was undertaken both in the shallow APC and in the deeper XCB intervals. High-frequency differences are abundant, particularly between the unsmoothed data from Holes $817 \mathrm{~A}$ and $817 \mathrm{~B}$. Indeed, Figure 3 suggests that a smoothing at least as long as the 10-point smoothing employed at Site 823 enhances signal-to-noise ratio. The lower-frequency character of adjacent holes exhibits fair replicability at Site 817 and good replicability at Site 823 . The replicability is not sufficient to permit detailed adjustment of core depths through interhole correlation; susceptibility is more useful and much more accurate for this 

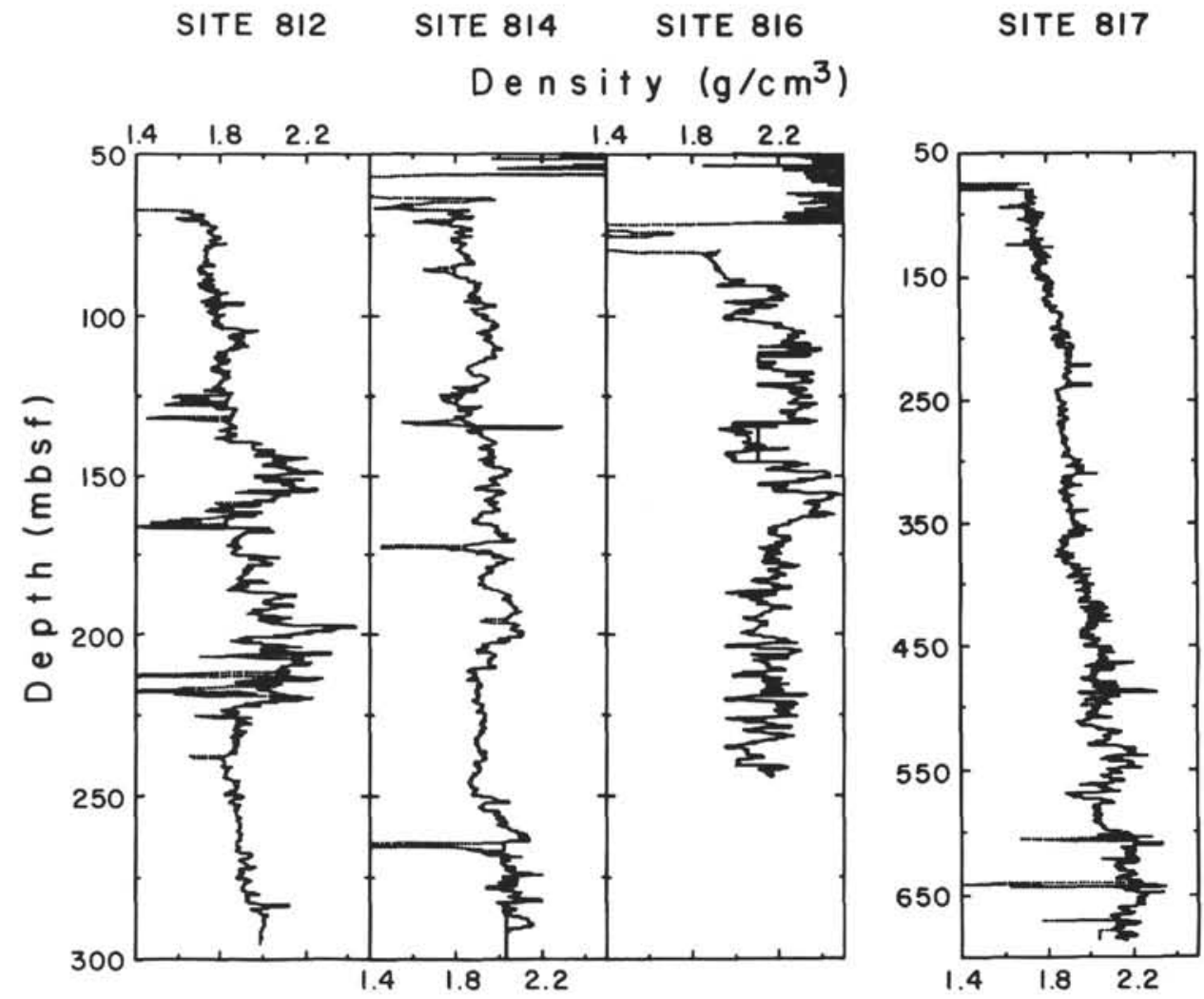

SITE 815

SITE 819

SITE 820

SITE 821

SITE 823

\section{Density $\left(\mathrm{g} / \mathrm{cm}^{3}\right)$}
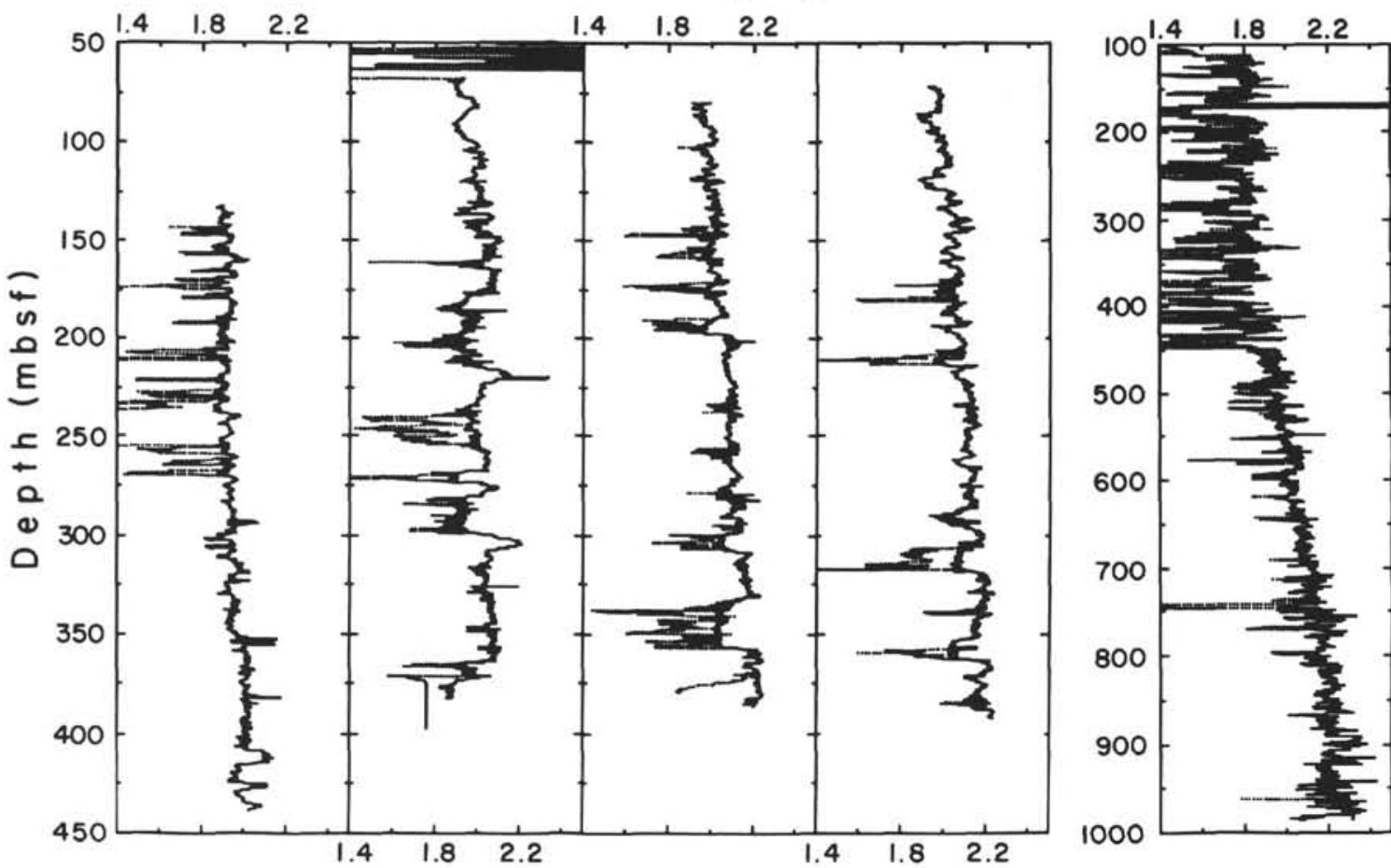

Figure 1. Downhole logs of bulk density. Dotted lines = raw logs. Note wide swings at some log tops, caused by tool entering pipe. Also note many density dropouts: spikes to very low apparent density caused by loss of pad contact with borehole wall. Solid line $=$ edited density log, which overlays reliable portions of raw log and replaces unreliable portions with pseudodensity calculated from resistivity. 


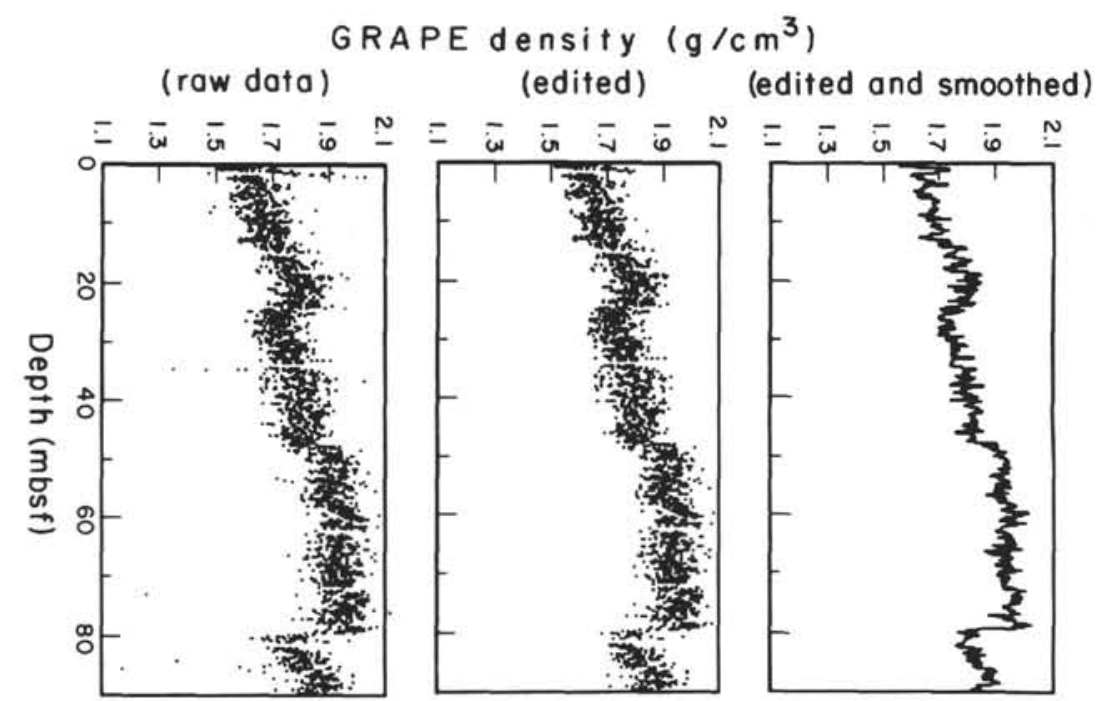

Figure 2. Example from Hole 823A of the editing of density dropouts employed before using the GRAPE density records obtained from whole core. Seventy-five points, or $3 \%$ of the raw data of the left plot, were deleted to produce the central plot. Ten-point smoothing of this central plot produces the final data of the right plot.
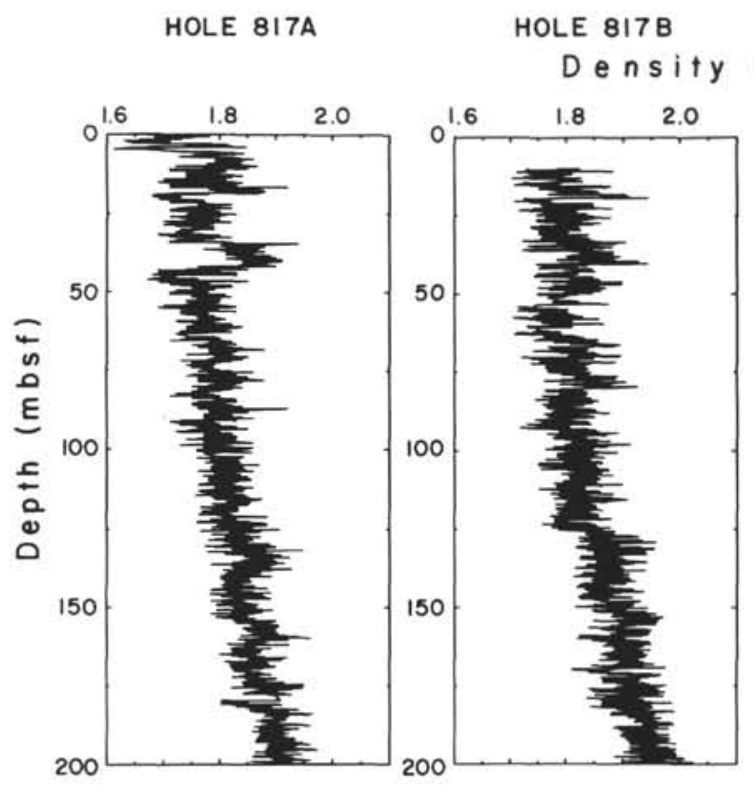
HOLE 823A $\mathrm{cm}^{3}$ )
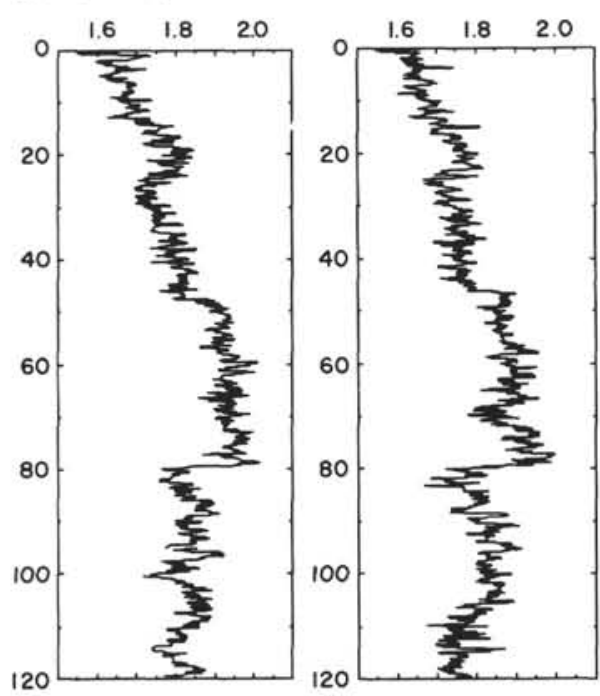

Figure 3. Examples of the consistency of edited GRAPE data from adjacent holes. Ten-point smoothing was applied to GRAPE data from Site 823 .

purpose. This replicability is sufficient, however, to permit edited GRAPE records to be useful for determining large-scale density variations of at least $0.1 \mathrm{~g} / \mathrm{cm}^{3}$ that persist over distances of $5 \mathrm{~m}$ or more.

Index measurements were performed at a typical spacing of $1.5 \mathrm{~m}$, wherever core recovery was moderately undisturbed. Approximately $10-\mathrm{cm}^{3}$ samples were weighed while wet, oven-dried, reweighed, their dry volumes then measured in a helium pycnometer, and bulk density, grain density, and porosity calculated. This measurement technique is described briefly by Shipboard Scientific Party (1991) and in more detail by Boyce (1976).

Because sampling for these index measurements deliberately avoids core disturbance, index bulk densities are more accurate than GRAPE densities. The disadvantage of index densities, compared to both GRAPE and log densities, is that the small measured volume may not be representative. Core recovery and disturbance can be biased toward certain porosities or lithologies. Even without such biases, one sample/1.5-m section provides a poorer estimate of both average density and density character than do the 40 to 50 GRAPE measurements in the same distance.

A comparison of index and edited GRAPE bulk densities for the logged Leg 133 sites (Fig. 4) permits several conclusions. First, the more continuous GRAPE densities are clearly much better for defining the character of density variations than are index densities at the standard $1.5-\mathrm{m}$ spacing. Intersample variability of spaced index densities appears to be so great that the longer wavelength variations are obscured; simple linear interpolation between index density measure- 

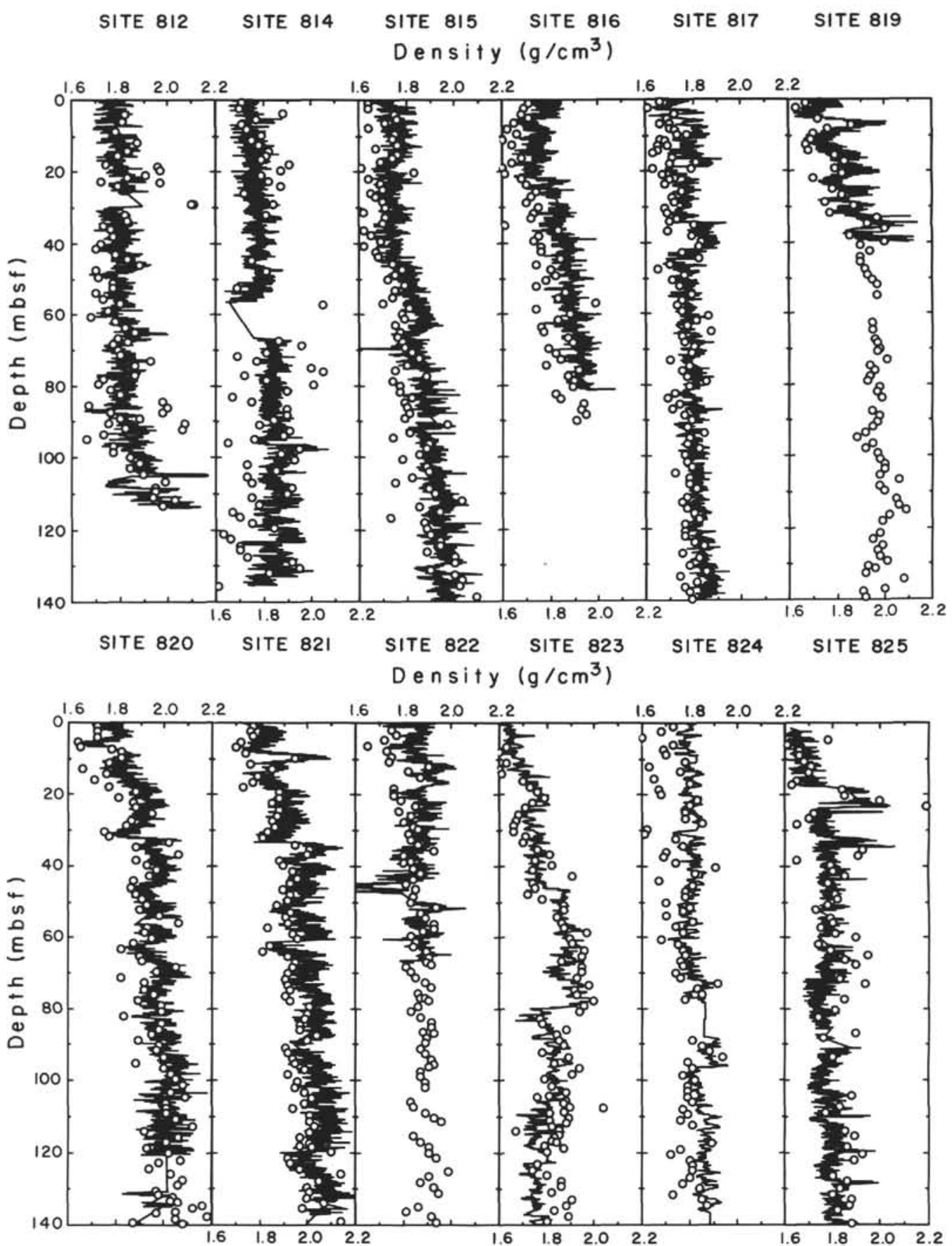

Figure 4. Overlay of index densities and edited GRAPE densities, for the top $140 \mathrm{mbsf}$ of each hole. Contrast the close similarity at some sites (e.g., Site 821) with the wide dispersion of index values in reefal sediments (Sites 812, 825, and lower 814). Also note that GRAPE is often systematically higher than index density.

ments might be highly misleading. For example, the adjacent peaks and troughs at 57-65 mbsf at Site 812 and at 95-98 mbsf at Site 814 are "detected" in index measurements only in hindsight; similar index-defined peaks and troughs at other depths in these sites are not confirmed by GRAPE measurements (Fig. 4). Exceptions to this generalization can be found: index densities faithfully reproduce GRAPE character at Site 821 (Fig. 4).

Second, index densities agree well with adjacent GRAPE densities in pelagic carbonates and in "mixed" (carbonate plus clay) sediments; Sites $815,817,820,823$, and particularly 821 are examples. However, the index densities are much more scattered and the similarity to
GRAPE densities much poorer in reefal carbonates (e.g., Sites 812 , 824 , and below $55 \mathrm{mbsf}$ at Site 814). This observation is consistent with observed porosity heterogeneity in the cores: the "reefal carbonate" cores are often composed of lithified cobbles of reef debris suspended in an unlithified matrix of pelagic carbonate, and discrete sampling cannot provide a representative sample of such materials.

Third, GRAPE densities sometimes exhibit a pervasive tendency to be slightly higher than the index densities. This pattern is most evident in Figure 4 for those sites at which GRAPE and index density characters match the best (e.g., Sites 817 and 821). The pattern can be examined at all sites by crossplotting index density vs. GRAPE 

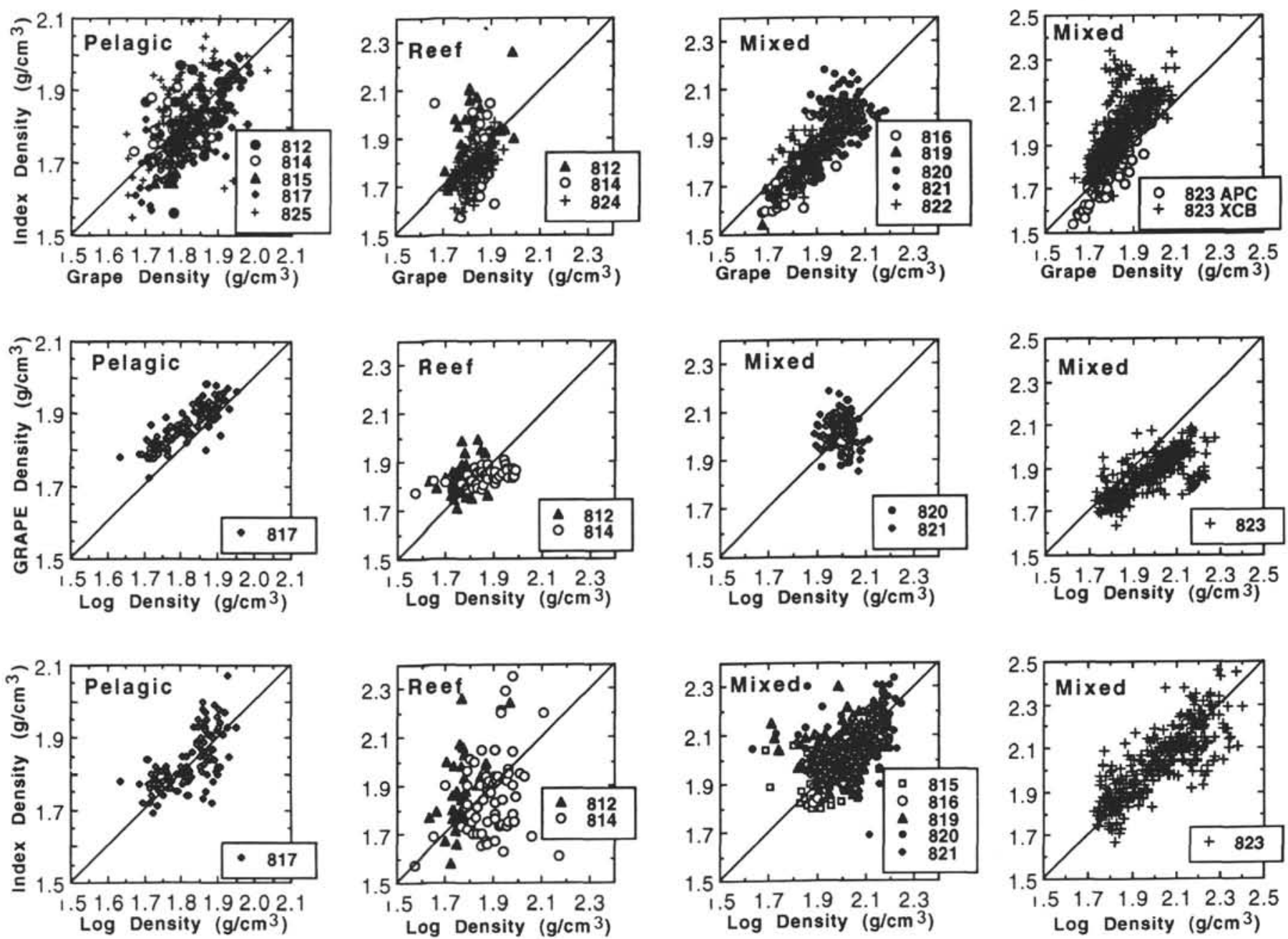

Figure 5. Crossplots comparing GRAPE density, index density, and log density for three broad lithologic classes: pelagic (pelagic calcium carbonate), reef (reef carbonates, often with intermixed pelagic carbonate), and mixed (dominantly pelagic carbonate, with substantial terrigenous fraction). Sites are indicated by number; data for Site 823 are so abundant that they are plotted separately.

density for the same depth (Fig. 5). The crossplots and depth plots suggest that GRAPE densities are $\sim 0.05$ to $0.10 \mathrm{~g} / \mathrm{cm}^{3}$ higher than index densities in the mixed-lithology sites and at carbonate Site 815 . However, GRAPE densities are slightly lower than index densities at Site 825 . We do not know the origin of this slight difference within APC cores. Nor does this comparison suggest to us which of the two measurement types is subject to the bias. We note, however, that the only significant population of XCB-cored data is at Site 823, where GRAPE densities are higher than index densities in APC cores and lower in XCB cores (Fig. 5). Because XCB core disturbance is more successfully avoided by index sampling than by GRAPE, this pattern suggests that GRAPE measurements in XCB cores slightly underestimate density because of slurry or void adjacent to the liner.

\section{REBOUND}

Density logging can provide a ground truth for evaluating which of the two core density measurements is more reliable. Caution is required, however, because even accurate core and log density measurements will disagree due to undetected core disturbance, undetected $\log$ errors, and especially, the core expansion that occurs due to the change from in-situ conditions to the warmer, lower-pressure environment of the laboratory.
Laboratory measurements of core porosity or density can be corrected to in-situ conditions if the amount of "rebound," or pressure and temperature-induced core expansion, is known. Ideally, consolidation tests should be used to determine the magnitude of this correction. Chen et al. (this volume) and Ladd et al. (this volume) present a few consolidation tests for Leg 133 sediments. Hamilton (1976) used consolidation tests for a variety of depths and lithologies to develop empirical estimates for the amount of rebound as a function of either depth or overburden for various types of deep-sea sediments. However, this correction is only approximate because experimental data for the effects of rebound are few and sediments vary dramatically in consolidation, even at the same depth and overburden. Diagenetic lithification reduces rebound; cherts and chalks can depart substantially from empirical curves of rebound vs. depth (Goldberg et al., 1987).

Several ODP studies have compared core and in-situ measurements of physical properties, to reach conflicting conclusions concerning rebound. For example, mechanically compacted terrigenous sediments of Site 646 agree well with Hamilton's (1976) rebound estimates, whether the correction is applied as a function of depth (Jarrard et al., 1989) or overburden pressure (Busch, 1989). However, Urmos et al. (1992) demonstrated that the rebound in pelagic carbonates from Leg 130 was much smaller than that estimated by Hamilton (1976). They reconciled core and log densities by correcting only for 
"hydraulic rebound": the 0.02 to $0.03 \mathrm{~g} / \mathrm{cm}^{3}$ decrease in density that is expected to result from expansion of the porewater. Nobes et al. (1991), in a study of pelagic carbonate sediments from Site 704, found no evidence of rebound. They suggested that core disturbance, not rebound, accounts for higher laboratory than in-situ porosities and that careful core sampling can avoid core disturbance and thereby remove the need for rebound correction. The impact that core disturbance can have on porosity is obvious during shipboard sampling; whether some unlithified sediments have escaped both rebound and any perturbation from core disturbance is more problematical.

Of relevance to this problem are efforts during some legs to produce a continuous composite sedimentary record by comparing and pasting together whole-core susceptibility records from adjacent holes. Although APC core recovery in each hole is typically about $104 \%$, these interhole comparisons indicate that 20 to $100 \mathrm{~cm}$ usually are missing from the bottom (or top) of a typical APC core (e.g., deMenocal et al., 1991). Thus, about $10 \%$ core expansion is hidden within some APC core recovery, and no systematic efforts have been undertaken to determine the scope of this problem. A 10\% core expansion decreases a typical APC density of $1.7 \mathrm{~g} / \mathrm{cm}^{3}$ by $0.06 \mathrm{~g} / \mathrm{cm}^{3}$.

In Figure 5, log measurements of density are compared to both index and GRAPE densities, at those depths for which all three data types are available. Within reefal and most mixed-sediment sites, the overlapping interval of GRAPE with log data is too short to exhibit substantial, useful density variation. Further, index variability is so extreme in reefal sediments that minimal correlation with log densities is usually observed. A useful comparison of index with $\log$ densities is possible in mixed and pelagic sediments (Fig. 5), and the two show reasonable agreement. In contrast, GRAPE values in APCcored sediments of Site 817 are higher than log values, while (as previously noted) GRAPE values in XCB-cored sediments of Site 823 are lower than $\log$ values. A plot of Site 817 densities as a function of depth (Fig. 6) reveals three patterns: a rough character match of features $>2$ to $4 \mathrm{~m}$ in wavelength, a 2-m depth shift between data sets, and a gradual decrease in density discrepancy with increasing depth.

Although the unresolved subtle offsets between GRAPE and both index and log densities are disturbing, we used GRAPE, rather than index measurements, for later merging with logs, because GRAPE provides a much more complete and accurate picture of the variations in density as a function of depth. In view of the unresolved offsets of 0.00 to $0.10 \mathrm{~g} / \mathrm{cm}^{3}$ and of uncertainties about core expansion, we did not apply the very subtle core expansion corrections of Urmos et al. (1992).

\section{MERGED CORE AND LOG DENSITY DATA}

At each of the nine sites that have a reliable density log, we merged core and log density data to obtain a continuous record of virtually the entire drilled interval (Fig. 7). GRAPE densities were smoothed with a 10-point running average, resampled at $0.15 \mathrm{~m}(0.3 \mathrm{~m}$ for deep-penetration Sites 817 and 823), and then merged with the edited density $\log$.

For depth intervals having both GRAPE and log data available, we generally considered the in-situ data to be more reliable and used these. Two exceptions to this generalization are found at Sites 817 and 823. In the overlapping region of Site 817, GRAPE and log character generally agree; yet GRAPE is $0.08 \mathrm{~g} / \mathrm{cm}^{3}$ higher than the density log at the 80.64 mbsf top of the density $\log$, with the discrepancy gradually decreasing with depth. At Site 817, we placed the GRAPE/log join at 205 mbsf, where the discrepancy was much smaller (Fig. 6). At Site 823 , hole conditions were ragged down to $\sim 450 \mathrm{mbsf}$. Rather than undertake massive editing of the poor-quality density log for $<450 \mathrm{mbsf}$ (Fig. 8), we utilized the GRAPE data, which (at least in the APC-cored interval) exhibit remarkably good replication (Fig. 3).

Table 1 shows the positions of joins of the different sources of density data at each site. None of the joins creates a sudden offset in density that could be misinterpreted as a major porosity change or that might create a seismic reflector in a synthetic seismogram. At Site 814 , an 11-m gap separates the deepest GRAPE data and the shallowest $\log$ data; the gap was filled by linear interpolation. At Site 819, the gap was almost $30 \mathrm{~m}$, and therefore at this site we used index densities in the merged density log.

\section{VELOCITY LOGS}

Velocity logging during Leg 133 used the Schlumberger longspaced sonic (LSS) tool on the geophysical tool string (Davies, McKenzie, Palmer-Julson, et al., 1991). At 0.15-m depth intervals, this tool measures four compressional wave traveltimes over sourcereceiver spacings of $2.4,3.0,3.0$, and $3.6 \mathrm{~m}$. Although traveltimes include the time for wave propagation both within the borehole and as a refracted wave along the borehole wall, the difference between traveltimes for different source-receiver spacings is a direct measure of the vertical velocity (inverse of traveltime) over a $0.61-\mathrm{m}$ interval of formation. Real-time Schlumberger processing yields two traveltime logs: a short-spaced (3.0-2.4 m) and a long-spaced $(3.6-3.0 \mathrm{~m}) \log$.

Within ODP, the Schlumberger-processed logs are seldom used, because of occasional strong bias by spurious traveltimes, caused by either noise or cycle skipping (e.g., Shipboard Scientific Party, 1987; Ellis, 1987). Instead, raw traveltimes are reprocessed to eliminate impossibly slow or fast traveltimes (Shipboard Scientific Party, 1987). Fortunately, the eight-measurement potential redundancy at each depth is sufficiently high, and most of the inaccurate traveltimes are sufficiently bizarre, that this simple reprocessing almost always salvages noisy sonic logs.

Sonic reprocessing for Leg 133 was undertaken on board the ship, and the reprocessed sonic logs shown in Davies, McKenzie, Palmer-

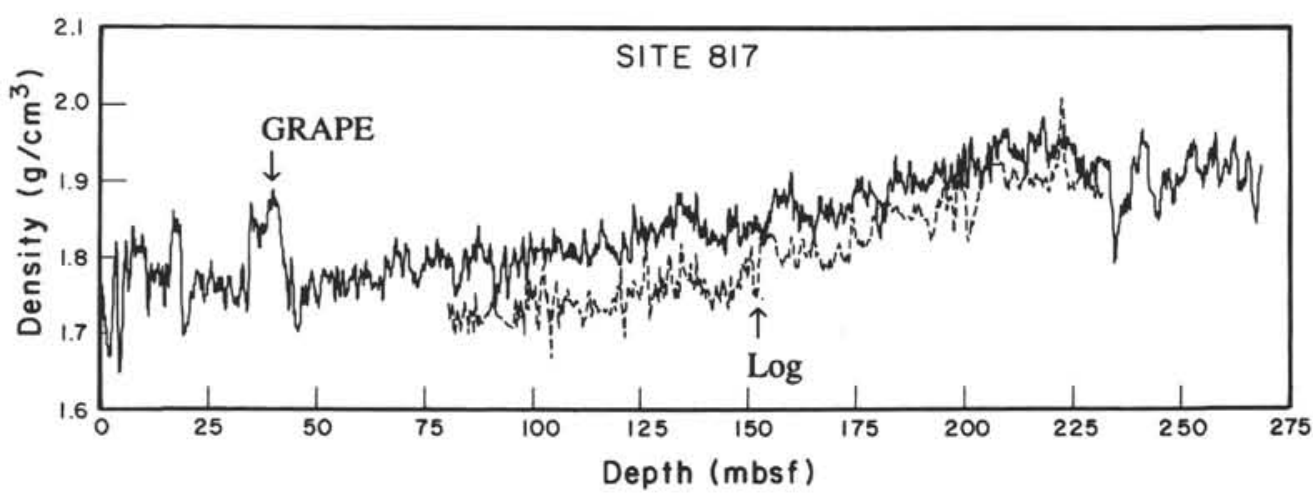

Figure 6. Overlay of GRAPE density record with downhole density log for Site 817, where an anomalous, unexplained offset of the two data sets is observed. 


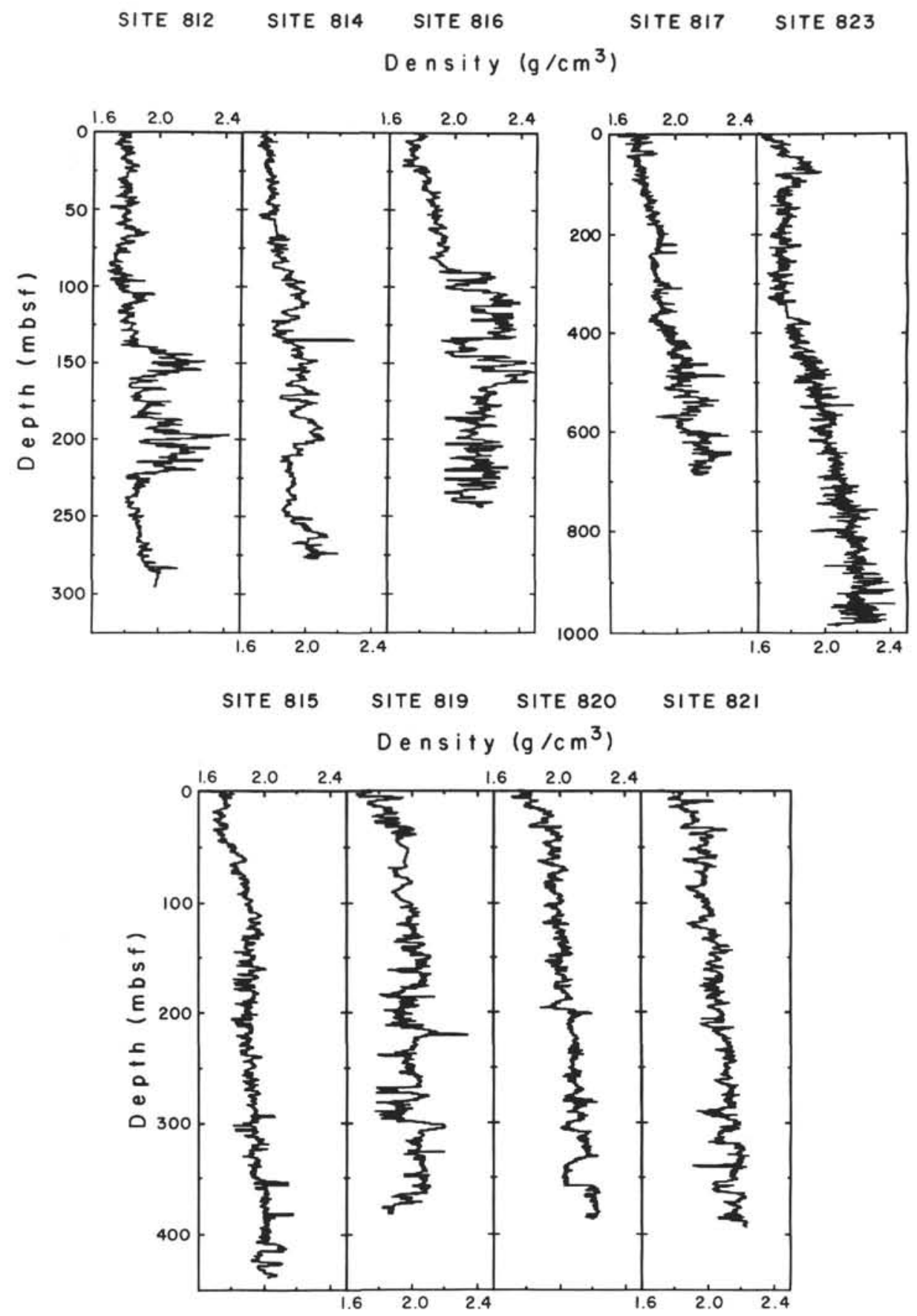

Figure 7. Best estimate of variations of bulk density with depth at each site, based on merging of edited GRAPE, index, density $\log$, and pseudodensity (from resistivity) $\log$ measurements. Positions of joins between different data types are given in Table 1.

Julson, et al. (1991) are those used here. At only one site, Site 816, were the sonic data so noisy that even the reprocessed sonic log had numerous unreliable intervals. At this site, we found that resistivity exhibited a close character match to the sonic log, except in those intervals that we had independently considered to have had a dubious sonic log. Therefore, we replaced the sonic log with a pseudosonic $\log$, based on regression of sonic on the logarithm of resistivity in intervals free of dubious sonic data, and application of the regression equations to the entire resistivity log (Davies, McKenzie, PalmerJulson, et al., 1991).
A similar pseudosonic approach was applied to the bottom few meters of each site, because the resistivity tool is the lowest tool on the tool string and, therefore, a few meters of resistivity log were obtained beneath the bottom of each sonic log. An exception is Site 814, where the link between sonic data and resistivity near the bottom of the hole was too poor to warrant the assumption of a linear relationship. We consider the least reliable portion of bottom pseudosonic log to be that at Site 824 , because the basal unit reached only by the resistivity tool is different in lithology than the overlying interval in which the sonic/resistivity relationship $(\mathrm{R}=-0.885)$ was determined. Jackson et 
GRAPE

LOG
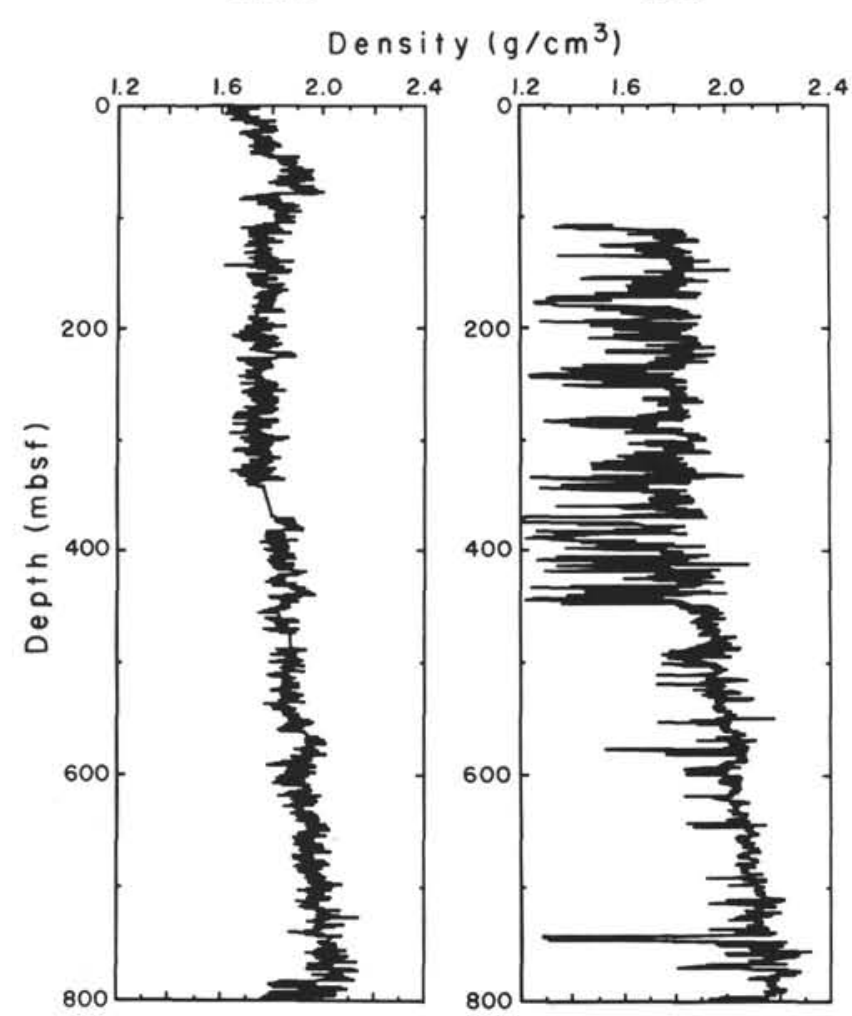

Figure 8. Comparison of edited GRAPE density data (left) with unedited downhole density $\log$ (right) at Site 823 , the site with the least accurate density log used in this study. Note the prevalence of density dropouts on the log above 448 mbsf, where the caliper log shows very poor hole conditions; these upper $\log$ data were discarded and the GRAPE data were used instead.

Table 1. Depth intervals of different types of density data used for establishing the final merged density record for each site.

\begin{tabular}{lcccc}
\hline Site & $\begin{array}{c}\text { GRAPE } \\
\text { depths } \\
\text { (mbsf) }\end{array}$ & $\begin{array}{c}\text { Index } \\
\text { depths } \\
\text { (mbsf) }\end{array}$ & $\begin{array}{c}\text { Density log } \\
\text { depths } \\
\text { (mbsf) }\end{array}$ & $\begin{array}{c}\text { Pseudodensity } \\
\text { (from resistivity) } \\
\text { (mbsf) }\end{array}$ \\
\hline & & & & \\
812 & $0.2-72.2$ & & $72.4-288.8$ & $288.9-295.8$ \\
814 & $0.2-56.6$ & & $67.8-285.8$ & $285.9-292.2$ \\
815 & $0.2-132.9$ & & $133.0-423.4$ & $423.5-439.1$ \\
816 & $0.2-79.8$ & & $80.0-237.6$ & $237.7-244.4$ \\
817 & $0.3-204.7$ & & $205.0-679.0$ & $679.3-687.8$ \\
819 & $0.2-40.0$ & $40.8-68.4$ & $68.9-371.1$ & $371.3-382.4$ \\
820 & $0.2-80.8$ & & $81.0-370.1$ & $370.2-386.4$ \\
821 & $0.2-72.2$ & & $72.3-384.9$ & $385.0-392.8$ \\
822 & & Unreliable & \\
823 & $0.3-447.8$ & & $448.1-975.4$ & $975.7-987.0$ \\
824 & & & No log & \\
825 & & & No log & \\
\hline
\end{tabular}

Note that depths are shown to one significant digit, but sample spacing was $0.15 \mathrm{~m}(0.30 \mathrm{~m}$ for Sites 817 and 823$)$, and depth-shift uncertainty between core and logs is $\sim 0.2-0.5 \mathrm{~m}$.

al. (this volume) discuss in more detail the relationship of velocity to resistivity, as well as the control of both parameters by porosity and cementation style within these sediments.

The accuracy of the sonic log was independently tested at one site. At Site 820, a checkshot survey was run with the Schlumberger vertical seismic profile tool. The total one-way seismic traveltime between the shallowest ( $93.8 \mathrm{mbsf}$ ) and deepest ( $334.6 \mathrm{mbsf}$ ) checkshots differs from that determined by integrating the sonic log by $<1$ ms (Davies, McKenzie, Palmer-Julson, et al., 1991), approximately the accuracy of individual checkshot traveltimes. This agreement to within $0.5 \%$ is remarkable.

\section{CORE VELOCITY}

Shipboard measurement of core velocity was undertaken at 4-m spacing, whenever cores were relatively undisturbed. Samples having volumes of from 10 to $20 \mathrm{~cm}^{3}$ were cut, and vertical compressional wave velocity was measured in a Hamilton-Frame velocimeter, which measures traveltime between two transducers clamped to opposite sides of the sample. The technique is described briefly in Shipboard Scientific Party (1991) and in more detail by Boyce (1976).

Our confidence in the reliability of Hamilton-Frame measurements for soft sediments is minimal. Velocities of soft sediments are very sensitive to subtle changes in elastic moduli (Gassmann, 1951). Yet such changes are inevitable because of the coring process, the change from in-situ to laboratory pressures and temperatures, the cutting of samples for velocity measurement, and the squeezing of samples in the Hamilton Frame. We note that probe transducers inserted into the split core have been found to be more successful for velocity measurement in soft sediments (Kroenke, Berger, et al., 1991).

Velocity measurements as a function of pressure are the most reliable technique for recovering the in-situ velocity of a sample that has undergone core expansion due to pressure release. This approach is far too time-consuming for shipboard measurements, but Chen et al. (this volume) have undertaken such measurements for 10 samples from Sites 815 and 817 . Implicit in such studies, as well as in measurements of bulk modulus as a function of pressure (Chen et al., this volume), is the assumption that elastic moduli have been decreased only by pressure release, not by core disturbance.

In unlithified terrigenous sediments at Site 646, Jarrard et al. (1989) found that pseudovelocities based on index measurements were more accurate than Hamilton-frame velocities. Therefore, we examined the relationship between core densities and log velocities to determine whether an empirical density-to-velocity transform is feasible for Leg 133 sediments. Figure 9 shows that no relationship is evident between velocity and either index or GRAPE densities in reefal sediments. Lack of consistency among density data was previously observed in this lithology, presumably because of heterogeneity and nonrepresentative sampling.

For pelagic and mixed sediments, log velocity is correlated with both index and GRAPE densities (Fig. 9). The relationship varies, however, from site to site, probably because rigidity is not a simple function of porosity in the diagenetically variable sites drilled during Leg 133. Further, one cannot extrapolate the trends of Figure 9 to the lower velocities present above the logged interval, because the relationship between porosity and velocity is nonlinear at high porosities (Raymer et al., 1980; Jarrard and Symonds, this volume).

In Figure 10, we have compared core velocity measurements with logged velocities at the 12 sites. Most of these core-velocity measurements from shallow unlithified sediments yield almost the same value of $1.6 \mathrm{~km} / \mathrm{s}$. These velocities increase only very slightly with depth in the top $100 \mathrm{mbsf}$ (Fig. 10), partly because velocity is relatively insensitive to porosity variations in high-porosity sediments (Raymer et al., 1980; Jarrard and Symonds, this volume).

Many of the core measurements fall $\sim 0.2 \mathrm{~km} / \mathrm{s}$ lower than the overall velocity/depth trend. This pattern of discrepant data is most evident in reefal sediments (Sites 812,814 , and 824 ), but was observed to some extent in all sediment types. Most of the anomalously low velocities are less than the $1.5 \mathrm{~km} / \mathrm{s}$ velocity of seawater and are clearly erroneous. In view of the approximately constant amount of offset of these data, we suspect that the error was caused by cycle skipping. For the $500-\mathrm{kHz}$ signal used in the Hamilton Frame, one cycle skip in a $2.5-\mathrm{cm}$ sample should decrease a $1.6 \mathrm{~km} / \mathrm{s}$ velocity measurement to $1.42 \mathrm{~km} / \mathrm{s}$. Because the sample sizes are known, these measurements could be corrected for an assumed single cycle skip. Instead, however, we deleted these measurements in later analyses.

Virtually all core velocities are substantially lower than log velocities at similar depths. This pattern, seen in unlithified sediments from nearly all DSDP and ODP legs, reflects the lowering of rigidity 

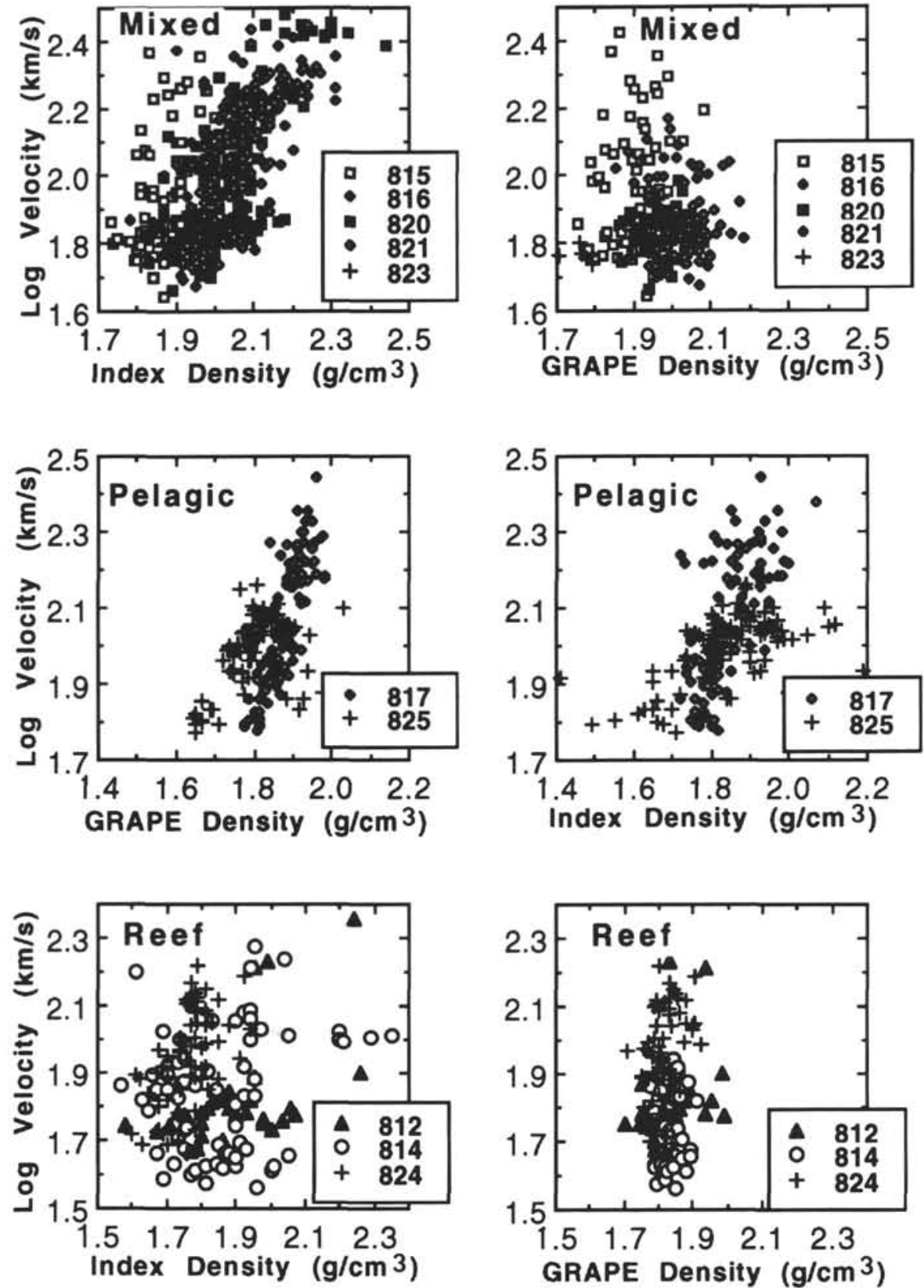

Figure 9. Crossplots comparing log velocity to index and GRAPE densities, to determine whether velocity can be predicted successfully from either density source. See Figure 5 for explanations of lithologic classes. Note the lack of any correlation in reef sediments, as well as the existence of only site-specific relationships between velocity and density in pelagic and mixed sediments.

associated with both rebound (Hamilton, 1979; Hamilton and Bachman, 1982) and core disturbance. If the rebound effect on velocity were simply caused by the porosity increase, then laboratory and log data should lie along the same trend on a crossplot of porosity vs velocity. Instead, laboratory and in-situ data define separate trends (e.g., Jarrard et al., 1989; Fulthorpe et al., 1989; Urmos et al., 1992), usually with higher in-situ than laboratory velocities for a given porosity. The same pattern is evident in Leg 133 sediments: although crossplots are not shown, the velocity/depth plots in Figure 10 exhibit much lower core velocities than log velocities, although index and log densities (and therefore porosities) are similar (Fig. 5). We, like these previous investigators, interpreted this excessive velocity rebound effect as having been caused by the major decrease in elastic moduli, particularly the skeletal (or frame) bulk modulus, caused by even a very small porosity increase or core disturbance.

Urmos et al. (1992) calculated an empirical correction for core velocity measurements from Site 807 , based simply on fitting a polynomial to the differences $(\Delta V$, in $\mathrm{km} / \mathrm{s})$ between core and $\log$ velocities as a function of depth $(Z$, in mbsf), as follows:

$$
\Delta V=1.31 \times 10^{-3} Z-8.7 \times 10^{-7} Z^{2} .
$$

They found that this correction achieved good agreement between core and in-situ velocities for all four analyzed sites on the Ontong Java Plateau. 

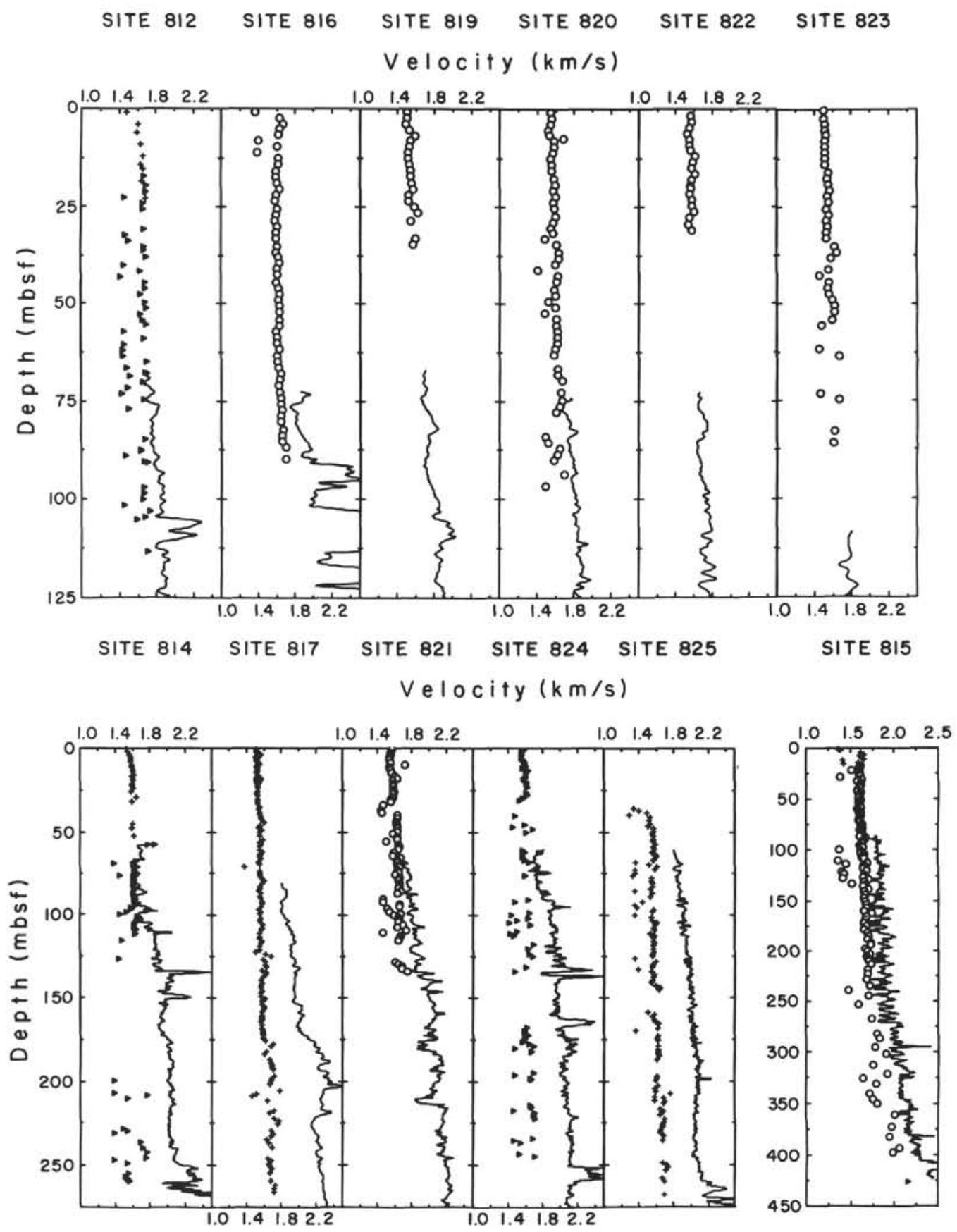

Figure 10. Comparison of the velocity log at each site with Hamilton-Frame velocity measurements in cores. Lithology symbols for Hamilton-Frame measurements: triangles (reef), circles (mixed), and pluses (pelagic); lithology classes are explained further in Figure 5. Note that all core velocity values are lower than log values, because of the lowering of frame rigidity by core disturbance and pressure changes.

As the Ontong Java sediments are pelagic carbonates, we anticipated that this empirical correction might work well for the pelagic carbonate sites of Leg 133, and perhaps moderately well for the "reefal carbonates" and "mixed" clay and carbonate, because most of the latter two lithologies are $>50 \%$ pelagic carbonate (Davies, McKenzie, Palmer-Julson, et al., 1991). Figure 11 is identical to Figure 10, except that core-velocity measurements have been corrected using Urmos et al.'s (1992) correction above. As with Figure 10, the suite of core measurements lying $0.2 \mathrm{~km} / \mathrm{s}$ lower (left) of each main trend is probably erroneous. Surprisingly, the correction does well for mixed sediments and most reefal sediments, yet substantially undercorrects for the lithology most similar to Ontong Java: the pelagic carbonate sediments of Sites 817 and 825 .

The empirical correction needed to reconcile core velocities to in-situ values is not only different at Sites 817 and 825 than at other Leg 133 sites and Ontong Java, it is also different between these two sites. Velocity discrepancies at Site 817 (Fig. 12) are fit by the linear relationship,

$$
\Delta V=0.0022 \times Z \text {. }
$$




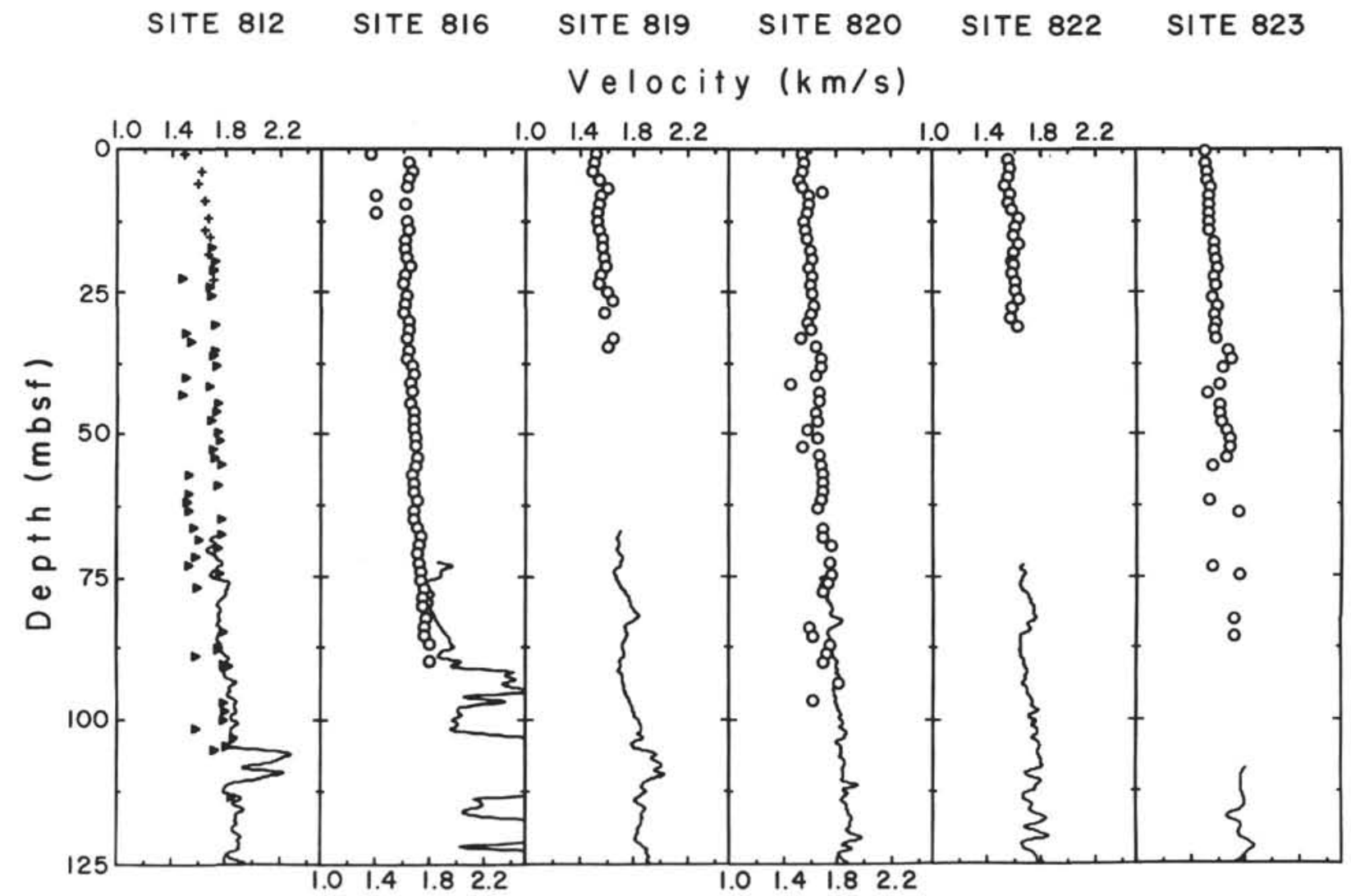

Figure 11. The same comparison of core and log velocity data as in Figure 10, except that all core velocities have been corrected for rigidity loss, using the empirical correction of Urmos et al. (1992).

\section{SITE 814 SITE 817 SITE $821 \quad$ SITE 824 SITE 825}

SITE 815

$\mathrm{Velocity}(\mathrm{km} / \mathrm{s})$
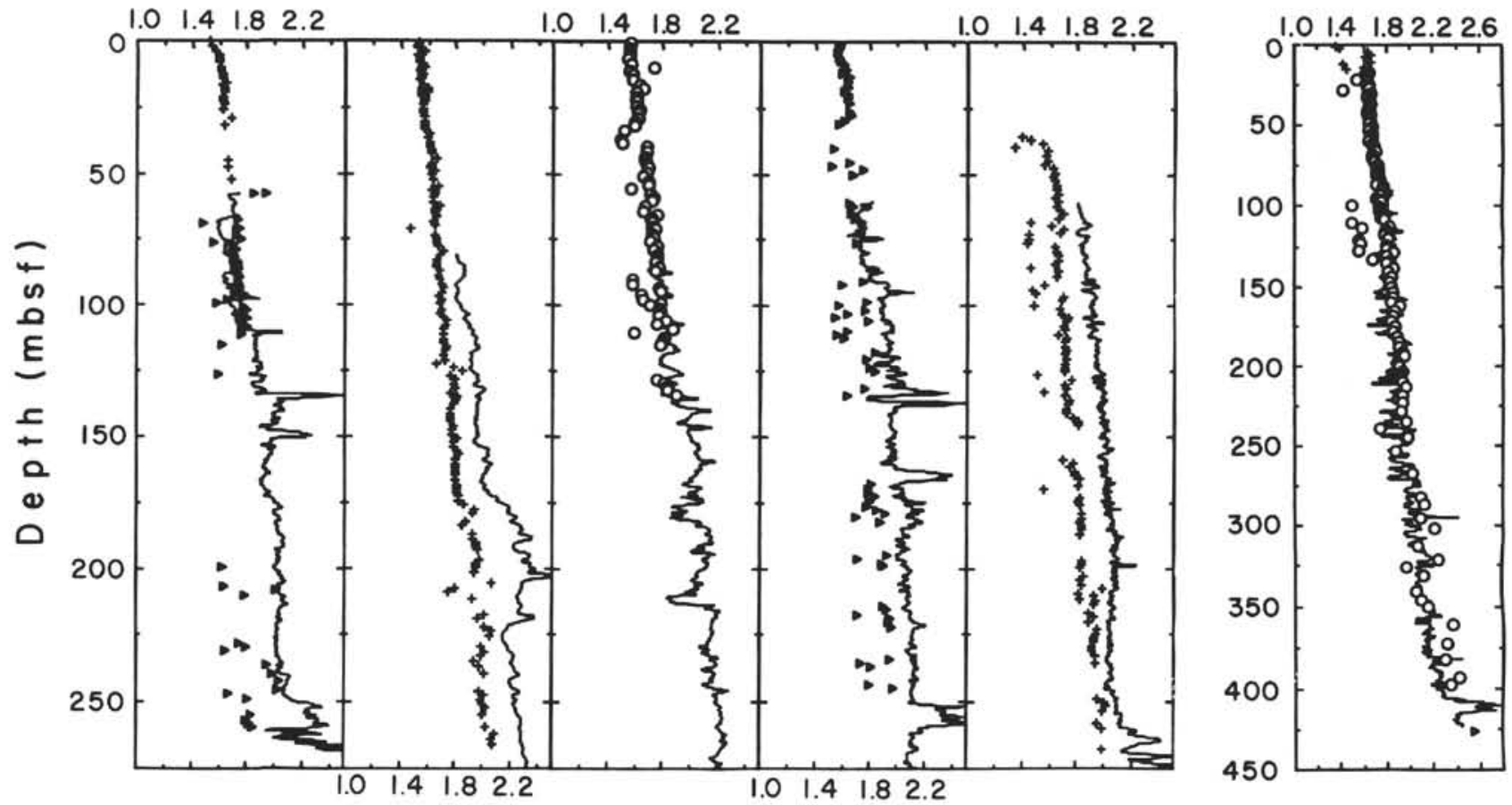

Figure 11 (continued). 


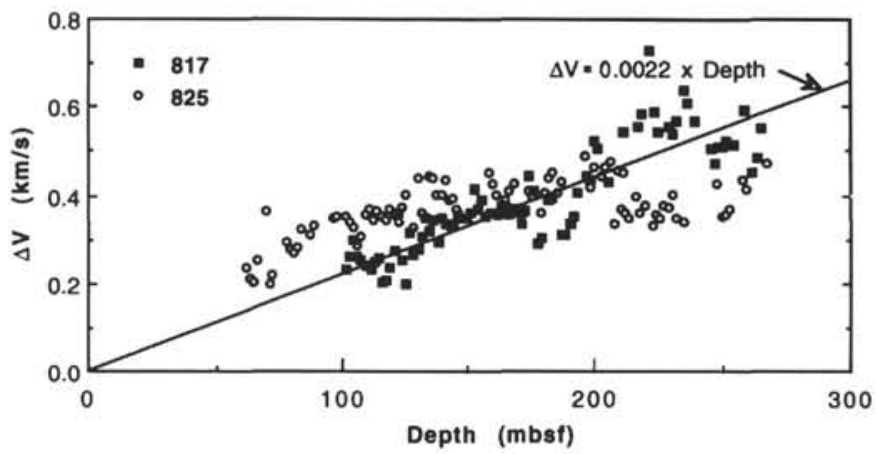

Figure 12. Development of a site-specific correction of core velocity for rigidity loss at Site 817 , based on simple regression of differences between core and $\log$ velocities $(\Delta V)$ as a function of depth. Note that the depth trend of $\Delta V$ at Site 825 is quite different.

For this short depth interval, a second-degree polynomial fit is unnecessary. For Site 825, a second-degree polynomial fit might be needed to achieve a value of $\Delta V=0$ at the seafloor. However, we have not corrected the Site 825 core data as too few core velocities are available above the logged interval to warrant their site-specific "correction" and merging with log data.

\section{MERGED CORE AND LOG VELOCITIES}

Core and log velocity data were merged at each site (Fig. 13), to produce a velocity log that extends from the seafloor to within a few meters of the bottom of the hole. First, core velocity data above the logged interval were corrected using Urmos et al.'s (1992) correction (Fig. 11) or, for Site 817, the Site 817 correction above. Second, we deleted anomalously slow core velocities, thought to have been caused by cycle skipping. Third, we deleted core measurements that, although possibly reliable, were so scattered that they would imply large-scale velocity variations when interpolation was used between widely spaced measurements; examples are the measurements at $40-50$ mbsf at Site 824 and at 60-75 mbsf at Site 823 (Fig. 11). Fourth, we interpolated and resampled the core velocities at a $0.15-\mathrm{m}$ spacing for most sites, and at a 0.30 -m spacing for deep-penetration Sites 817 and 823 . Finally, we merged the resampled core data with the log data, using linear interpolation across the missing-data intervals at Sites $819,822,823$, and 825 (Fig. 11). Depths of joins between the different data sources are given in Table 2.

In general, we consider that the final merged velocity logs of Figure 13 are nearly true in-situ velocities. The very heterogeneous and spiky character of parts of Sites 812 and 816 is probably real; it results from the extremely variable cementation in these reef carbonates, as evidenced by both resistivity logging and sparse core recovery. At depths below $100 \mathrm{mbsf}$ at these two sites, however, the magnitudes of some of the apparent velocity decreases to almost $1.5 \mathrm{~km} / \mathrm{s}$ may have been exaggerated by hole washout. Similarly, we suspect that some of the subtle velocity cyclicity observable between 125 and 275 mbsf at Site 815 (Fig. 10) and above 450 mbsf at Site 823 may have resulted from highly variable hole size. We have found that the LSS tool is remarkably, but not completely, immune to errors caused by hole-size variations. Thin spikes to very high velocity at Sites $814,817,819,822$, 824 , and 825 are probably real, based on confirmation by resistivity logs. All are likely to consist of cemented beds, some caused by cementation in situ and others by turbidite deposition of cemented reef debris.

The core-based portions of the final merged velocity logs are less reliable than the log-based portions, due to core disturbance and, particularly, the wide spacing of possibly nonrepresentative samples. Fortunately the insensitivity of velocity to porosity at these very high porosities suggests that errors are likely to be $<0.1 \mathrm{~km} / \mathrm{s}$, which is relatively small compared to the observed velocity variations at greater depths.
Table 2. Depth intervals of different types of velocity data used for establishing the final merged velocity record for each site.

\begin{tabular}{cccc}
\hline Site & $\begin{array}{c}\text { Core velocity } \\
\text { depths } \\
\text { (mbsf) }\end{array}$ & $\begin{array}{c}\text { Velocity log } \\
\text { depths } \\
\text { (mbsf) }\end{array}$ & $\begin{array}{c}\text { Pseudovelocity } \\
\text { (from resistivity) } \\
\text { (mbs) }\end{array}$ \\
\hline 812 & $0.2-67.7$ & $67.8-281.2$ & $281.3-295.8$ \\
814 & $0.2-57.3$ & $57.5-277.5$ & \\
815 & $0.2-86.1$ & $86.3-422.3$ & $422.5-440.3$ \\
816 & $0.2-72.2$ & & $72.4-244.4$ \\
817 & $0.3-99.1$ & $99.4-671.6$ & $672.0-687.8$ \\
819 & $0.2-34.5$ & $66.6-366.6$ & $366.7-382.4$ \\
820 & $0.2-73.9$ & $74.1-370.8$ & $371.0-386.4$ \\
821 & $0.2-66.1$ & $66.2-376.0$ & $376.2-392.8$ \\
822 & $0.2-31.1$ & $72.2-308.4$ & $308.5-324.7$ \\
823 & $0.3-85.7$ & $108.0-971.5$ & $971.8-987.0$ \\
824 & $0.2-28.0$ & $60.5-391.3$ & $391.5-407.2$ \\
825 & None & $61.4-434.8$ & $434.9-447.1$ \\
\hline
\end{tabular}

Note that depths are shown to one significant digit, but sample spacing was $0.15 \mathrm{~m}(0.30 \mathrm{~m}$ for Sites 817 and 823$)$, and depth-shift uncertainty between core and logs is $\sim 0.2-0.5 \mathrm{~m}$.

\section{CONCLUSIONS}

Detailed quality control, often leading to the deletion of erroneous data, is essential for integrating core and log physical-property measurements. Cycle skipping and noise, the principal problems encountered on the velocity log, were successfully removed for almost all sites during shipboard reprocessing. In unlithified carbonates, the drilling process enlarges hole size so much that density logging often loses pad contact, which results in density dropouts that must be subjectively identified and deleted. Overlaying a resistivity log on the density $\log$ aids in the identification of such dropouts. GRAPE density measurements exhibit similar pervasive washouts, caused by core disturbance and the breaks between core sections; these, too, must be deleted. Some Hamilton-Frame measurements of the velocity of unlithified sediments are adversely affected by cycle skipping, and all are exquisitely sensitive to reduction of frame modulus due to both core disturbance and rebound. Index measurements of core density, in contrast, are less sensitive to core disturbance and rebound; they appear to be accurate but, in heterogeneous sediments such as reef carbonates, not necessarily representative.

We think that this study has successfully integrated core and log physical-property measurements, by developing 12 merged velocity logs (Fig. 13) and 9 merged density logs (Fig. 7), each extending from the seafloor to within a few meters of the bottom of the hole. These merged logs can be used for depth-to-time conversion and can provide a detailed tie between each drill site and its regional seismic network.

\section{ACKNOWLEDGMENTS}

This study was supported by NSF Grant TAMRF No. 20539/ 20642 and by a grant from Atlantic Richfield Company.

\section{REFERENCES*}

Boyce, R.E., 1976. Definitions and laboratory techniques of compressional sound velocity parameters and wet-water content, wet-bulk density, and porosity parameters by gravimetric and gamma ray attenuation techniques. In Schlanger, S.O., Jackson, E.D., et al., Init. Repts. DSDP, 33: Washington (U.S. Govt. Printing Office), 931-958.

Busch, W.H., 1989. Patterns of sediment compaction at Ocean Drilling Program Sites 645, 646, and 647, Baffin Bay and Labrador Sea. In Srivastava, S.P., Arthur, M., Clement, B., et al., Proc. ODP, Sci. Results, 105: College Station, Texas (Ocean Drilling Program), 781-790.

\footnotetext{
- Abbreviations for names of organizations and publication titles in ODP reference lists follow the style given in Chemical Abstracts Service Source Index (published by American Chemical Society).
} 
Davies, P.J., McKenzie, J.A., Palmer-Julson, A., et al., 1991. Proc. ODP, Init. Repts., 133: College Station, TX (Ocean Drilling Program).

deMenocal, P., Bloemendal, J., and King, J., 1991. A rock-magnetic record of monsoonal dust deposition to the Arabian Sea: evidence for a shift in the mode of deposition at $2.4 \mathrm{Ma}$. In Prell, W.L., Niitsuma, N., et al., Proc. ODP, Sci. Results, 117: College Station, TX (Ocean Drilling Program), 389-407. Ellis, D.V., 1987. Well Logging For Earth Scientists: New York (Elsevier).

Fulthorpe, C.S., Schlanger, S.O., and Jarrard, R.D., 1989. In situ acoustic properties of pelagic carbonate sediments on the Ontong Java Plateau. $J$. Geophys. Res., 94:4025-4032.

Gassmann, F., 1951. Elastic waves through a packing of spheres. Geophysics, 16:673-685.

Goldberg, D., Wilkens, R.H., and Moos, D., 1987. Seismic modeling of diagenetic effects in Cenozoic marine sediments at Deep Sea Drilling Project Sites 612 and 613. In Poag, C.W., Watts, A.B., et al., Init. Repts. DSDP, 95: Washington (U.S. Govt. Printing Office), 589-599.

Hamilton, E.L., 1976. Variations of density and porosity with depth in deep-sea sediments. J. Sediment. Petrol., 46:280-300.

1979. Sound velocity gradients in marine sediments. J.Acoust. Soc. Am., 65:909-922.

Hamilton, E.L., and Bachman, R., 1982. Sound velocity and related properties of marine sediments. J. Acoust. Soc. Am., 72:1891-1904.

Han, D., Nur, A., and Morgan, D., 1986. Effects of porosity and clay content on wave velocities in sandstones. Geophysics, 51:2093-2107.

Jarrard, R.D., Dadey, K.A., and Busch, W.H., 1989. Velocity and density of sediments of Eirik Ridge, Labrador Sea: control by porosity and mineralogy. In Srivastava, S.P., Arthur, M.A., Clement, B., et al., Proc. ODP, Sci. Results, 105: College Station, TX (Ocean Drilling Program), 811-835.
Kroenke, L.W., Berger, W.H., Janecek, T.R., et al., 1991. Proc. ODP, Init. Repts., 130: College Station, TX (Ocean Drilling Program).

Nobes, D.C., Mwenifumbo, C.J., Mienert, J., and Blangy, J.P., 1991. The problem of porosity rebound in deep-sea sediment cores: a comparison of laboratory and in-situ physical-property measurements, Site 704, Meteor Rise. In Ciesielski, P.F., Kristoffersen, Y., et al., Proc. ODP, Sci. Results, 114: College Station, TX (Ocean Drilling Program), 711-716.

Raymer, L.L., Hunt, E.R., and Gardner, J.S., 1980. An improved sonic transit time-to-porosity transform. Trans. SPWLA 21st Annu. Log. Symp., Pap. P.

Shipboard Scientific Party, 1987. Site 645. In Srivastava, S. P., Arthur, M., et al., 1987. Proc. ODP, Init. Repts., 105: College Station, TX (Ocean Drilling Program), 61-418.

, 1991. Explanatory notes. In Davies, P.J., McKenzie, J.A., PalmerJulson, A., et al., Proc. ODP, Init. Repts., 133: College Station, TX (Ocean Drilling Program), 31-58.

Urmos, J., Wilkens, R.H., Bassinot, F., Lyle, M., Marsters, J., and Mayer, L., in press. Laboratory and well-log velocity and density measurements from the Ontong Java Plateau: new in-situ corrections to laboratory data for pelagic carbonates. In Berger, W.H., Kroenke, L.W., Mayer, L.A., et al., Proc. ODP, Sci. Results, 130: College Station, TX (Ocean Drilling Program).

Date of initial receipt: 12 April 1992

Date of acceptance: 21 July 1992

Ms 133B-267 
$\begin{array}{llllll}\text { SITE } 812 & \text { SITE } 814 & \text { SITE } 816 & \text { SITE } 822 & \text { SITE } 817 & \text { SITE } 823\end{array}$

$\mathrm{Velocity}(\mathrm{km} / \mathrm{s})$
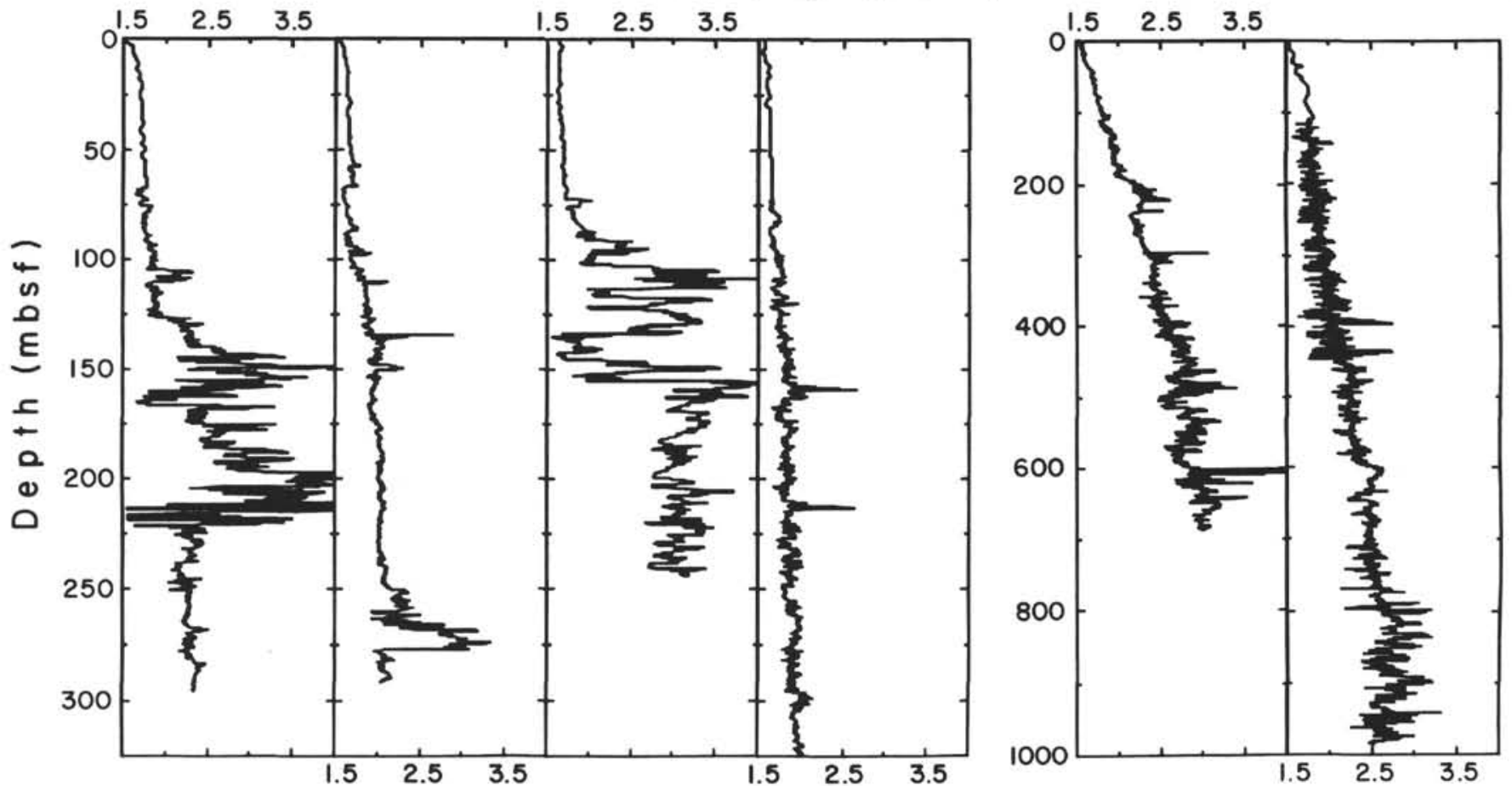

Figure 13. Best estimate of variations of velocity with depth at each site, based on merging of rebound-corrected core velocities with the velocity and pseudovelocity (from resistivity) log. Positions of joins between different data types are given in Table 2.

$\begin{array}{llllll}\text { SITE } 815 & \text { SITE } 819 & \text { SITE } 820 & \text { SITE } 821 & \text { SITE } 824 & \text { SITE } 825\end{array}$

$\mathrm{Velocity}(\mathrm{km} / \mathrm{s})$

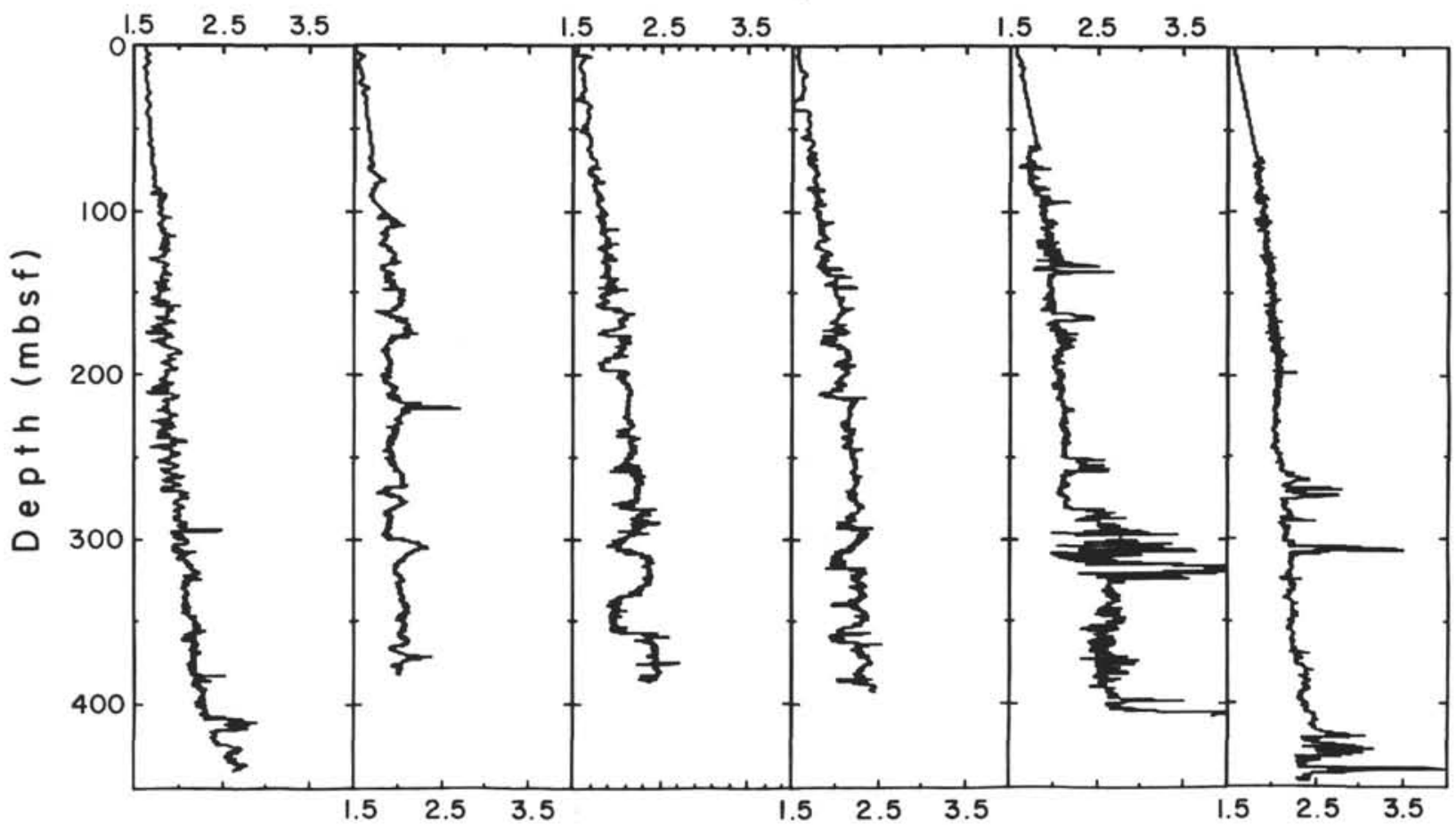

Figure 13 (continued). 